\title{
Grandes y pequeños: microestructuras narrativas en la Crónica do Imperador Beliandro
}

Recibido: 14/05/2014

Aceptado: 15/09/2014

\section{RESUMEN:}

El presente trabajo constituye un breve análisis de la construcción narrativa de la Crónica do Imperador Beliandro, una novela de caballerías escrita en lengua portuguesa en el siglo XVII y atribuida por la tradición bibliográfica a la condesa da Vidigueira, D. Leonor Coutinho de Távora. El artículo estudia la inserción de unidades narrativas como historias interpoladas, cartas y otros microtextos, y su interrelación con otros géneros de la época como la literatura sentimental y la pastoril.

PALABRAS CLAVE: novela de caballerías - microestructuras - historias interpoladas

\section{ABSTRACT:}

This paper is a short analysis of the narrative construction of the Crónica do Imperador Beliandro, a chivalric romance written in Portuguese in the seventeenth century and attributed by the bibliographical tradition to the Countess of Vidigueira, D. Leonor Coutinho de Távora. The article studies the inclusion of narrative units such as interpolated stories, letters and other microtexts, and its interrelationship with other contemporary genres such as the sentimental or pastoral literature.

KEY WORDS: chivalric romance - microstructures - interpolated stories 
À ce moment de sa narration,

Schaharazade vit apparaître le matin, et, discrète, se tut.

Les Mille et Une Nuits (traducción de J. C. Mardrus)

\section{Un género en constante evolución}

En Las mil y una noches, los diversos cuentos narrados por Sherezade al cruel rey Shariar están cuidadosamente engarzados a modo de cajas chinas, es decir, se trata de relatos intercalados en una historia principal que les sirve de marco y que genera la aparición de nuevas estructuras narrativas subordinadas, como si se tratara de cajas encerradas en el interior de otras cajas de mayor tamaño. Este paradigma se remonta a los albores de la tradición oral persa e hindú y ya está presente en las series de cuentos del Panchatantra y otros textos de la literatura en lengua sánscrita. En relación con las transformaciones experimentadas entre los siglos XVI y XVII por la literatura de caballerías —un género dilatado en el tiempo y sometido a constante evolución-, el crítico portugués João Palma-Ferreira sugería un paulatino desarrollo de cuadros de intrigas novelescas que siguen un modelo preestablecido y plagado de estereotipos — basados en la "semelhança das situações" - , a la par que detectaba un notable aprovechamiento y reutilización de tramas inspiradas en las novelas pastoriles y sentimentales ${ }^{1}$. Otro elemento que enriquece el desarrollo estructural del género - tan permeable a las novedades y a los cambios en el gusto del público contemporáneo- es la frecuente inserción de composiciones líricas en el entramado narrativo ${ }^{2}$.

1 Palma-Ferreira, João. Temas de Literatura Portuguesa, Lisboa, Verbo, 1983, págs. $58-59$.

2 La presencia de composiciones líricas en el texto de la Crónica do Imperador Beliandro es muy notable. Al respecto puede consultarse el siguiente artículo: Álvarez-Cifuentes, Pedro: "Ecos cancioneriles en la novela seiscentista: el ejemplo de la Crónica do Imperador Beliandro", Voz y letra: revista de literatura, XXIII/2, 2012, págs. 3-18. Otra técnica narrativa muy característica de los libros de caballerías de la Edad 
Todas estas tendencias pueden ser estudiadas en detalle al analizar los niveles estructurales de textos de mediados del siglo XVII como la Crónica do Imperador Beliandro, una novela de caballerías escrita en lengua portuguesa que circuló manuscrita y ha sido atribuida por la tradición bibliográfica a la pluma de la condesa da Vidigueira, D. Leonor Coutinho de Távora (muerta en 1648).

En efecto, el narrador del Beliandro — cuyo principal eje narrativo es el enfrentamiento entre el príncipe D. Belindo de Portugal y el príncipe Belifloro de Grecia por el amor de una orgullosa y voluble dama, la princesa Leridonia de Francia - hace referencia en varias ocasiones a la necesidad de multiplicar los hilos narrativos del relato para "fazer esta [história] mais aprazível na variedade dos sucessos" (II, 32) ${ }^{3}$. Sin embargo, consciente de que tampoco conviene abusar de la atención de los lectores, rehúsa relatar por extenso las aventuras de personajes secundarios como la amazona Delfina de Inglaterra, los caballeros Artauro de Bohemia, Polibio de Macedonia, Felismino de Roma y Florimante de Persia o la princesa Claricia de Mauritania, entre otros muchos, para lo que remite a la obra de plumas ajenas:

Algumas aventuras thes acontecerão no caminho, de que se não dá conta porque, como a História não hé sua, trata o autor de não a interromper com obras alheas, e mais porque os cronistas dos seus reinos nos têm dado particulares notícias das maravilhas do seu valor (II, 35).

de Oro consiste en el viejo juego del historiador fingido, un procedimiento metaficcional que tiene su primer origen en las historias troyanas de Dares el Frigio y Dictis de Creta y que ha sido bien estudiado a través de la figura del árabe Cide Hamete Benengeli referido por Cervantes en el Quijote.

3 En el presente trabajo, citaremos el texto de las dos primeras partes de la Crónica do Imperador Beliandro a partir del ms. 875 de la colección de los “Manuscritos da Livraria" del Arquivo Nacional da Torre do Tombo, en Lisboa (ANTT 875). 
A pesar de esta voluntad expresa de focalizar la narración en las hazañas de los personajes principales, los príncipes D. Belindo de Portugal y Belifloro de Grecia, heredero del trono imperial de Constantinopla - “quem tem o primeiro lugar nesta Crónica" (II, 27)—, cabe señalar el virtuosismo narrativo que supone la intercalación progresiva de diversas historias y nouvelles en la trama principal de la Crónica do Imperador Beliandro, un recurso similar a la estructura de cajas chinas que generalmente se opone a la bien estudiada técnica del entrelacement - cuyo origen se remonta a los romans artúricos medievales y que supone una alternancia de planos narrativos que propician la simultaneidad temporal de los eventos relatados ${ }^{4}$ - . Así, la coda de la mayor parte de los capítulos del Beliandro hace referencia al salto de las peripecias de un personaje a las de otro, entrelazándolas y conformando una arquitectura narrativa bastante ambiciosa, como muestran los siguientes ejemplos: "deixaremos a Corte ocupada por darmos conta do que aconteceo aos príncipes" (I,1); "os deixaremos caminhando para hum lugar em que pudesse ser curado, por darmos conta de outros acontecimentos que chamão por nós" (I, 5); “onde os deixaremos por dar rezão das princezas, que deixámos no centro da terra" (I, 23); "nesta pena o deixa a História até que seja força tornar a dar rezão dela" (I, 37); "assi os deixa a História, os cavaleiros caminhando, os emperadores fazendo gente para o socorro, por darmos conta de como a donzela de Lindomena chegou a Constantinopla" (II, 10); "assi as deixaremos em quanto Ganiménia estuda, por darmos conta do nosso portuguêz, que deixámos em seguimento do cavaleiro que levava a peregrina" (II, 46); "onde os deixaremos por dar conta de quem este cavaleiro era e das rezões que ali o trouxerão" (II, 49).

4 Según el profesor Cacho Blecua, "el entrelazamiento consiste [...] en el relato de una, dos o más historias pertenecientes a personas diferentes y ocurridas en distintos espacios, en la mayoría de las ocasiones en tiempos simultáneos, contada — contadas - interrumpidamente, para ser recogida — recogidas - en la detención siguiente", véase Cacho Blecua, José Manuel. "Introducción", Amadís de Gaula, I, Madrid, Cátedra, 1987, pág. 178. 
Para el especialista italiano Ettore Finazzi-Agrò, el resultado de estos procedimientos de entrelacement es "uma narração onde vários planos se intersectam entre si, da qual o autor [...] maneja os cordéis, conseguindo manter a atenção do leitor sempre viva através de antecipações ou atrasos da acção, por intermédio, afinal, de todos aqueles mecanismos que farão, muito mais tarde, a fortuna dos romances de aventuras ou dos policiais"

Aunque ambas técnicas son modalidades del procedimiento de "amplificación material"6 que afecta a la mayor parte de las novelas de caballerías de los siglos XVI y XVII, el entrelazamiento contrasta de manera patente con el modelo narrativo de las "historias contadas", en el que el personaje "se convierte en narrador de su propia historia, por lo que desaparece la simultaneidad temporal" 7 . Suele tratarse de personajes secundarios y actantes que se cruzan con los protagonistas del relato a lo largo de sus frecuentes viajes y peripecias y aprovechan para enunciar su historia de forma retrospectiva, ofreciendo nuevas informaciones o nuevos actantes que a menudo revolucionan el desarrollo de la trama, enriqueciendo sus posibilidades. Para Emilio Sales Dasí, "en su uso reiterado las historias contadas irán adquiriendo cada vez un mayor grado de independencia o autonomía que en cierto modo estará preparando el camino para las historias intercaladas" ${ }^{\prime \prime}$.

5 Finazzi-Agrò, Ettore. A Novelística Portuguesa do Século XVI, Carlos Moura, trad., Lisboa, Instituto de Cultura Portuguesa, 1978, pág. 27.

6 Green, James Ray: "La forma de la ficción caballeresca del siglo XVI", Actas del VI Congreso Internacional de Hispanistas, Evelyn Rugg y Alan M Gordon, Toronto, eds., Universidad de Toronto, 1980, págs. 353-355.

7 Cacho Blecua, José Manuel: “El entrelazamiento en el Amadís y en las Sergas de Esplandián", Studia in honorem prof. Martín de Riquer, I, Barcelona, Quaderns Crema, 1986, pág. 256.

8 Sales Dasí, Emilio José: “Las «historias contadas» en el libro de caballerías", Revista de Poética Medieval, 7, 2001, pág. 98. 
Como es bien sabido, la inclusión de relatos no constituye ninguna novedad en la tradición caballeresca. El propio Miguel de Cervantes "había respaldado [...] la intercalación de relatos ajenos a la trama principal por el placer que proporciona la variedad, equiparando los episodios exteriores a la propia historia principal" ${ }^{\prime \prime}$. En consonancia con la preceptiva aristotélica, la Philosophía Antigua Poética de López Pinciano recomendaba, en efecto, perseguir la variedad dentro de la unidad, ya que "la naturaleza se goza con la variedad de las cosas y [...] este animal fábula será también más deleitoso, cuanta más variedad de pinturas en él se vieren"10. Martínez Mata destaca cómo, en el caso del Quijote, fueron precisamente los episodios intercalados los que primero despertaron el interés del público ${ }^{11}$.

\section{Las historias interpoladas en el Beliandro}

Simplificando la sistematización que propone Sales Dasí12, distinguiremos dos tipos fundamentales dentro de estas "historias contadas". El tipo (A) se reviste de un carácter retrospectivo, ya que los personajes principales vuelven a encontrarse después de una separación justificada por el argumento y se narran los unos a los otros las aventuras transcurridas durante ese periodo a modo de recapitulación. Según Sales Dasí, este tipo no implica ninguna virtualidad narrativa sino meramente informativa, y tiene menos interés desde el punto de vista de la técnica. El segundo tipo (B) resulta más innovador, ya que supone la aparición de un nuevo personaje, ajeno a la narración hasta ese momento

9 Martínez Mata, Emilio. Cervantes comenta el Quijote, Madrid, Cátedra, 2008, pág. 140.

10 López Pinciano, Alonso. Philosophía Antigua Poética, II, Alfredo Carballo Picazo, ed., Madrid, Centro Superior de Investigaciones Científicas, 1953, pág. 53.

11 Martínez Mata, E., Cervantes..., pág. 145.

12 Sales Dasí, E. J., “Las «historias contadas»...”, págs. 98-99. 
y que cuenta su historia personal para solicitar la ayuda de los protagonistas o, por lo menos, provocar su interés, su simpatía o su compasión. En este caso, Sales Dasí estima que "la historia que se rememora no sólo cumple una función informativa, sino que exige una rápida intervención del caballero y se proyecta, por tanto, hacia el futuro", potenciando la complejidad estructural del relato ${ }^{13}$.

Como ya apuntábamos, en el caso de la novela que nos ocupa las "historias contadas" aproximan la narración a otros géneros literarios ajenos a la tradición caballeresca tales como la narración sentimental o la pastoril. Hemos localizado hasta diez ejemplos de historias interpoladas del tipo (B) en las dos primeras entregas de la Crónica do Imperador Beliandro. En la Primera Parte hallamos cuatro muestras de "historias contadas" o digresiones narrativas —normalmente de extensión bastante breve- que se apartan del núcleo principal de la rivalidad entre Belifloro y D. Belindo, a saber:

1. La historia de Alcidonia, princesa de Tracia, secuestrada de casa de su padre por el gigante Tramorlante el Cruel, señor de la Isla Calfúrnea, que la lleva prisionera a la corte de Constantinopla, donde, una vez liberada por el príncipe Belifloro, cuenta el relato de su cautiverio a los emperadores de Grecia (I, 9).

2. La historia de Delfina, princesa de Inglaterra, que tras presentarse en el torneo de Marte en la Floresta de las Flores disfrazada del Caballero de los Álamos, es derrotada por Rolindo de Alemania y narra a las princesas de Grecia cómo fue nombrada

13 Sales Dasí, E. J., “Las «historias contadas»...”, pág. 99. El mismo estudioso propone un tipo (C) de "historias contadas", que consistiría en la siguiente circunstancia: "En la corte se presenta una doncella o un embajador en busca de un paladín que le ayude a él o a un allegado a salir de una difícil situación cuyas causas describe con mayor o menor lujo de detalles". Consideramos que, grosso modo, esta modalidad constituye una variante del tipo (B) anteriormente enunciado. 
caballero por su padre tras librar a la familia real del ataque de unos gigantes traicioneros (I, 15).

3. La historia de Pinaflor, la hija perdida del rey de Navarra, enamorada del infante navarro Rodearte, que en realidad es su hermanastro aunque ninguno de los dos lo sabe. Cuando su abuelo materno - el desposeído duque de Cartagena- le revela su verdadero origen, Pinaflor huye del amor incestuoso y no puede resistirse a contar la historia de sus pesares a las princesas de Grecia:

—Sabeis pedir tão bem, minhas senhoras [...] que vos não poderei negar o que dezejais saber sem arriscar a cortezia que se deve a que vejo em vossas pessoas e, posto que referir mágoas seja o mesmo que torná-las a padecer de novo, por vos obedecer tornarei a pôr a risco o sofrimento. E porque hé larga a tragédia de minha vida assentai-vos e ouvireis a mais lastimosa história que em tão poucos anos se podia imaginar (I, 15).

4. La historia de Felisaura, la hija del difunto Almirante de Inglaterra, que, abandonada tras haber sido seducida por el ingrato rey inglés - el hermano de la amazona Delfina, que ahora pretende contraer matrimonio con la infanta Lindoniza de Portugal, la hermana de D. Belindo-, sale en busca de su amante disfrazada de escudero y cuenta, involuntariamente, su triste historia al sultán Aliaduz de Babilonia, que la sorprende llorando en el claro de un bosque:

-Deveis, Senhor Cavaleiro, de ter ouvido as minhas queixas — disse a que parecia homem-, que eu fiava só do silêncio destas ágoas, com que me não fica lugar de fingimento para vos negar quem sou, e também servirá de obrigação o confessar-vo-lo para merecer a mercê que me fazeis nos oferecimentos com que me tendes empenhada a vos confessar o que não sahio ategora das praças de minha alma (I, 32). 
En la Segunda Parte del Beliandro, hemos localizado otros seis ejemplos de "historias contadas", que son los siguientes:

5. La historia de Clarifebo, príncipe de Tartaria, que narra su enamoramiento "de oídas" de la emperatriz Lindomena de Niquea a los emperadores de Grecia (II, 4).

6. La historia de Felismino, el nuevo emperador de Roma, que cuenta a D. Belindo sus amores de juventud con su prima Doribea de Nápoles durante las bodas de la emperatriz Lindomena de Niquea con el tártaro Clarifebo:

D. Belindo, em quanto Clarifebo lograva favores de despozado, passava ele com o cavaleiro com quem teve a batalha, de quem soube era filho do emperador de Roma, tão valeroso como ele experimentou tanto à custa do seu sangue, tão discreto como cada dia conhecia melhor na conversação que tinhão. Dezejava muito de saber que rezões o trouxerão aonde o achara, e assi lhe perguntou pedindo-lhe com as melhores palavras lhe não negasse a ocasião que o tinha tão desviado da terra donde nacera. Ele que lhe não sabia já negar nada pelo como o tinha obrigado o seu bom termo, lhe disse assi (II, 10).

7. La historia de Cleófilo, príncipe de Castilla, que cuenta a D. Belindo sus amores por su prima la princesa Polidora de Aragón y su conflicto con el príncipe Floramán de Sicilia durante la travesía rumbo a Samarcante en auxilio del sultán Aliaduz:

Huma tarde que por ser de grande calma estavão todos na varanda por tomar melhor o fresco, lhe disse D. Belindo:

-Não vos pedi até agora, Senhor Cavaleiro, a palavra que me destes de me dizerdes quem éreis, porque quiz primeiro que vos dissesse o trato destes senhores que podeis fiar deles o que prometestes de me não negar a mim. Eles vos merecem toda a confiança que fizerdes deles, e não vos desmereço eu a mercê que me fareis em me não dilatar mais o saber quem sois. 
A que respondeo o das Borboletas:

-Quizera, Senhor Cavaleiro do Sofrimento, fazer mais por vós que o dizer quem sou, para assi poder desempenhar a obrigação que vos confesso, e a estes senhores. Mas no que me mandais vos obedeço. Meu nome hé Cleófilo, sou filho herdeiro de El-Rei de Castela [...] (II, 15).

8. La historia de Florimante, príncipe de Persia, que - bajo la identidad del Caballero Triste- narra al curioso D. Belindo la historia de sus amores con la princesa Claricia de Mauritania y su conflicto con el caballero Estanislao de Fenicia durante dos noches consecutivas:

Despertou o cavaleiro e levantando-se donde estava lhe disse:

- Se os males de que me queixo poderão ter remédio, já mo prometera na mercê que me vôs fazeis. Ela me servirá de alívio se alcançar por eles o vosso conhecimento. E se vos parece que mereço dizerdes-me quem sois, deixareis paga a estimação que faço de mo averdes de dizer. termo:

A que o nosso portuguêz respondeo, muito pago do seu bom

- Mal vos poderá, senhor, negar nada quem assi vos vem buscar. Eu sou D. Belindo de Portugal, tão pouco conhecido no mundo que não deve de aver chegado à vossa notícia quem eu sou, mas com que saibais que desde que fui armado cavaleiro assisto na Corte do Emperador entendereis vós que, pelo que dela se ouve nos mais remotos reinos, que não posso desmerecer o dizerdes-me o vosso nome, que o ver-vos tão igual comigo no com que vos dais a conhecer me faz dezejar mais saber o em que vos posso servir.

-Em verdade, senhor D. Belindo, que me deixais obrigado a dizer-vos quem sou e a dar-vos conta da minha vida, mas hé ela tal que até referida atemoriza. No que me tendes dito de vós me seguro que não correrão perigo no vosso silêncio as desventuras a que devo segredo como honrado e que devia calar por maiores respeitos.

Tornou-lhe a dizer D. Belindo: 
-Certo, senhor, que com menos cautelas poderdes fiar de mim a rezão das vossas queixas, porque quando não possais achar remédio delas na minha desgraça, achareis pelo menos hum coração muito aparelhado para vos ajudar a sentir e huma alma muito honrada para saber calar o que vós me mandardes que não diga.

A que respondeo o Triste:

- Sabeis pedir tão bem, senhor D. Belindo, que não posso faltar ao que vós me mandais (II, 23).

9. La historia de Clorilenia, princesa de Macedonia y hermana de Polibio, que narra a Belifloro sus amores con Leonido de Polonia, sobrino de la emperatriz Lusbea, y el cautiverio de ambos al servicio de la princesa Zelidaura de Fez (II, 28).

10. La historia de la peregrina Lusbea, princesa de Bretaña, que relata su enamoramiento del príncipe Polibio de Macedonia a las princesas de Grecia, con las que se encuentra en los jardines del Palacio de las Maravillas:

Com muito discretas rezões lhes agradeceo a peregrina as com que a tinhão tão obrigada e que para saber a quem devia tanto lhe fizessem mercê de lhe dizer quem erão, a que satisfazerão nomeando-se todas, e que pois a tinhão satisfeita dizendo-lhe o que dezejara saber que já lhes estava devendo o não lhes negar quem era, posto que já as tinha advertido o seu parecer e o seu trato que era muito mais do que o seu traje parecia. Foi a reposta dezatar-se a corrente às lágrimas, que por muito espaço lhe não deixarão articular palavras e, como pôde falar, alimpou os olhos com hum grande e fino lenço de Cambrai, pedindo-lhes mil perdões de as aver molestado, disse:

- Referir desgraças que estão vivas na memória para a atormentar, inda que não seja renovar penas, porque sempre são iguais para o sentir, hé pelo menos atemorizar o crédito de se ver segunda vez a lanço de se desautorizar. Mas que dificuldades não rompe o preceito de vossa obediência? E a quem podeis vós mandar que não 
arrisque tudo por vos obedecer? Sou a desgraciada Lusbea, Princeza de Bretanha, a quem a Fortuna deu estado para o destruir, deu calidade para a desluzir, deu entendimento para o deixar sem desculpas! (II, 45).

Huelga explicar que las "historias contadas" presentes en la Crónica do Imperador Beliandro resultan un tanto repetitivas -incidiendo a menudo en dos esquemas narrativos básicos: (1) un caballero se siente atraído por una amiga o pariente cercana, que vacila en favorecer sus requiebros o rechazarlos, pero que luego se enamora repentinamente del mejor amigo del caballero, provocando un claro conflicto que a veces desemboca en un desenlace feliz y otras veces no, y (2) una dama que es secuestrada o violentada por un gigante o malhechor pero que finalmente será rescatada in extremis por un caballero del que se enamora apasionadamente- y aproximan la narración al campo de la novela sentimental, al desarrollar un argumento de temática generalmente amorosa. De todas formas, los relatos intercalados en el Beliandro siempre tienen una vinculación más o menos estrecha con la historia principal de las hazañas de D. Belindo y Belifloro y sirven para expandir sus aventuras o introducir nuevos personajes que viajan a la corte de Constantinopla para rendir sus homenajes al emperador Beliandro. En la Segunda Parte, otra modalidad de "episodios intercalados" sería, por supuesto, el relato de la estancia de D. Belindo y la princesa Leridonia en el Valle de los Pastores, que -además de establecer un contraste con respecto a la ambientación cortesana de Constantinoplarecrea todas las convenciones del género pastoril.

\section{Otras microestructuras narrativas}

Apunta Tobias Brandenberger que "los libros de caballerías fueron desde muy pronto una tradición que con alguna facilidad acogía en sus complicadas y largas narraciones también insertos o subtramas alogenéricos, además de trozos heterodiscursivos 
tales como cartas, carteles de desafío o poemas"14. En efecto, la frecuente inserción de cartas y epístolas en el tejido narrativo de la Crónica do Imperador Beliandro se inspira, claramente, en una tradición establecida en obras anteriores ${ }^{15}$. En este sentido, contabilizamos hasta dieciséis ejemplos a lo largo de las dos primeras partes de la novela - en concreto, cinco en la Primera y once en la Segunda ${ }^{16}$ - , que incluyen cartas de amor desesperado, como

14 Brandenberger, Tobias. La muerte de la ficción sentimental. Transformaciones de un género iberorrománico, Madrid, Verbum, 2012, pág. 352.

15 Sobre "la formación de una temática epistolar propia a la novela caballeresca, con sus motivos básicos y sus variantes circunstanciales", véase Roubaud, Sylvia y Joly, Monique: "Cartas son cartas. Apuntes sobre la carta fuera del género epistolar", Criticón, 30, 1985, págs. 104-112, un artículo en el que las autoras trazan la diferencia entre cartas de información, cartas de desafío, cartas de petición y cartas de amor, con diversos ejemplos tomados de las novelas castellanas. Opinaba D. Francisco de Portugal sobre la labor epistolar en su Arte de Galantería (1670): “Será la carta breve y llana y ligera, un lugar entre lo mismo enamorado que libre todo el caudal en lo discreto; las razones medidas y la letra sin borrones. De ninguna manera se irá a lo de Guárdeme Dios a Vuestra Merced, la firma sin guardas. En todo lo de palacio, que lo de un corazón traspasado de una saeta quédase para las de amores, adonde todo el ingenio es fraile. En la primera y en las demás son mejores las más nescias" (véase Portugal, Francisco de. Arte de Galantería, José Adriano de Freitas Carvalho, ed., Porto, Centro Inter-Universitário de História da Espiritualidade - Universidade do Porto, 2012, pág. 148). También en Corte na aldeia (1619), disertará Francisco Rodrigues Lobo sobre "a polícia e estilo das cartas missivas" y "a maneira de escrever e [a] diferença das cartas missivas" (véase Lobo, Francisco Rodrigues, Corte na aldeia, José Adriano de Freitas Carvalho, ed., Lisboa, Presença, 1992, págs. 72 y 88).

16 Los textos epistolares que aparecen en las dos primeras partes del Beliandro son: una carta de Arideo al emperador Beliandro para consolarle por la desaparición de sus hijos (I, 1), una carta amorosa de Rodearte a Pinaflor y la respuesta de la pastora (I, 15), una misiva del rey de Inglaterra a Felisaura y la contestación de la dama (I, 32), el desafío de la morisma (II, 8), una carta de Arideo a D. Belindo para pedirle que acuda a rescatar a la emperatriz Lindomena de Niquea (II, 9), una nota de Arideo a D. Belindo y Belifloro a su llegada a Samarcante (II, 16), el reto del Caballero Triste (II, 23), dos cartas de amor de Florimante a Claricia y sus respectivas contestaciones (II, 23), un mensaje de Arideo al rey de Francia (II, 34), una carta de Arideo a D. Belindo con el retrato de Gracelinda de Niquea (II, 48) y las confesiones amorosas que el enano Enil arrebata al príncipe de Portugal (II, 51). Observamos que, sin contar a los amantes, es el Sabio Arideo el que más recurre en la novela a la comunicación epistolar, como corresponde a un observador externo de los acontecimientos narrados. 
la que dirige Rodearte a la pastora Pinaflor a través de una amiga que actúa como medianera:

Tantos anos de vida malgastados são cutelos da vida e tiranos do entendimento, que quem em nacendo não soube atinar a servirvos não merecia entradas para adorar-vos. Mas vós, senhora, que valeis este conhecimento, aceitai por reparos da inocência os estremos do maior amor, que quando lhe não devais satisfação ao menos não lhe podeis negar as lástimas (I, 15).

A pesar de su reclusión motivada por la muerte de su padre en combate contra los holandeses, también Felisaura y el rey de Inglaterra se intercambiam misivas de alto voltaje sentimental con la tácita complicidad de los hijos de su nodriza:

Amar-vos hé crédito de quem vos vio, confessar-vo-lo hé perder o merecimento, que o poder não grangea confiança onde o amor se faz respeito. Só espero que entendais que não ofende em adorar-vos quem não espera mais que permitirdes que vos sirva (I, 32).

El papel de los confidentes e intermediarios resulta esencial a la hora de analizar la comunicación epistolar que se establece entre los personajes del Beliandro. Pero en la novela atribuida a la condesa da Vidigueira también constan ejemplos de correspondencia diplomática, como la carta de desafío que envían los reyes de la morisma al emperador de Grecia para declararle la guerra:

A Emperatriz de Babilónia, Lucano Emperador da Grão Turquia, o Grão Sofi da Pérsia, os Califas de Hicónia e Alepo, os Reis de Arménia, de Calcidónia, de Argel, de Fez, de Epiro, Narsinga e do Cairo, e os mais Reis nossos valedores e vassalos, fazemos saber a Vós, Emperador de Constantinopla, que pelos grandes agravos que por permissão dos Deuzes temos recebido de vós e de vossos cavaleiros, vos desafiamos a todos os reis cristãos. 
De oje a seis mezes, com todo o poder de nossos estados, estaremos nessa barra onde poderá ser vos arrependais do que vos devíeis persuadir vos não pediríamos conta.

Os Deuzes sejão em vossa guarda (II, 8).

Estos ejemplos sirven para certificar la complejidad narrativa que se aborda en la Crónica do Imperador Beliandro, común a otros textos del mismo género. No hallamos en el Beliandro, sin embargo, ningún rastro de la técnica narrativa consistente en superponer múltiples puntos de vista sobre un mismo acontecimiento, cuyo uso destaca Nanci Romero ${ }^{17}$ en otras novelas coetáneas como la Crónica de D. Duardos de Gonçalo Coutinho. En cualquier caso, y a pesar de la frecuente reiteración de temas y motivos, mediante la técnica de la amplificación material los libros de caballerías ganan en riqueza argumental —ampliando los personajes y las peripecias - y en perspectiva narrativa, ya que la voz particular de cada uno de los personajes relatores sustituye, durante un periodo de tiempo, la del narrador principal. En este sentido, cabe destacar que seis de los diez narradores de "historias contadas" engarzadas en la trama del Beliandro son personajes femeninos (las damas Alcidonia, Delfina, Pinaflor, Felisaura, Clorilenia y Lusbea), lo que atrae nuestra atención acerca de la presencia en el texto de una fuerte preocupación por los problemas específicos de las mujeres y la necesidad de expresar su voz a lo largo de la historia. Al analizar la voz narrativa que subyace en las novelas sentimentales castellanas, Alan Deyermond observaba que en ninguna de ellas encontraba "a una mujer que sea narradora principal, aunque sí hay mujeres que narran dentro del cuadro de una narración en voz masculina"18.

17 Romero, Nanci. Edição da Crónica de D. Duardos (Segunda e Terceira Partes), tesis de doctorado, Universidade de São Paulo, 2012, págs. 70-71.

18 Deyermond, Alan: "El punto de vista narrativo en la ficción sentimental del siglo XV", Actas del I Congreso de la Asociación Hispánica de Literatura Medieval, Vicente Beltrán, ed., Barcelona, Promociones y Publicaciones Universitarias, 1988, pág. 47. 
La única excepción sería la protagonista narradora de la Menina e moça del portugués Bernardim Ribeiro.

\section{Conclusiones: la novela como compendio}

Mª Carmen Marín Pina ha argumentado que los libros de caballerías peninsulares resultan "un compendio, una enciclopedia de los géneros del momento, cuyas características y rasgos estilísticos se diluyen y confunden en el discurso monológico que recorre todos los textos ${ }^{\prime 19}$. Esta inserción de unidades narrativas de tipo y funciones muy variadas se hace patente en la Crónica do Imperador Beliandro. Entre grandes y pequeños, macro y microestructuras de tipología muy variada, la novela gana en interés para los lectores —que ven interrumpido el relato por digresiones narrativas que potencian su irresistible curiosidad, a la manera de la astuta Sherezade en Las mil y una noches-, al mismo tiempo que las perspectivas de análisis se ven expandidas y multiplicadas.

En la misma medida, el tema amoroso es otro de los ejes que vertebran la ficción caballeresca desde la época del Amadís de Gaula. Esta temática amorosa está impregnada frecuentemente de un erotismo muy sutil, muy estilizado y casi inexistente en el caso del Beliandro. También en la Argonáutica da Cavalaria destaca Vargas Díaz-Toledo "la ausencia de erotismo, un elemento característico de los libros de caballerías castellanos en su difusión manuscrita" ${ }^{20}$. Apunta Finazzi-Agrò al respecto:

a concepção amorosa - [...] em consequência da Contra-Reforma- virá ligar-se cada vez mais ao estereótipo neo-platónico da

19 Marín Pina, Maㅡ Carmen. Edición y estudio del ciclo español de los Palmerines, tesis de doctorado, Universidad de Zaragoza, 1988, pág. 407.

20 Vargas Díaz-Toledo, Aurelio. Edición crítica y estudio del Leomundo de Grécia, de Tristão Gomes de Castro, tesis de doctorado, Universidad Complutense de Madrid, 2007, pág. 187. 
mulher inaccesível, enquanto o erotismo latente do modelo se esfumará num sensualismo estetizante, tão caro à poética maneirista ${ }^{21}$.

Aparte de las narraciones de temática sentimental o pastoril, Vargas Díaz-Toledo detecta en el Beliandro una cierta tendencia hacia la representación teatralizada de determinados episodios:

as aventuras cavaleirescas são postas de lado para dar lugar a um mundo teatralizado no qual os elementos sensoriais e sensitivos têm bastante relevância. Os fogos-de-artifício, assim como os dispositivos mecânicos, adquirem um lugar de relevo no qual o feiticeiro se converte no director de uma incessante sucessão de maravilhas, num dei ex machina capaz de tudo ${ }^{22}$.

\section{Para Anna Bognolo, en el ciclo de los Palmerines}

le vicende d'amore, offuscate solo a tratti da disavventure dovute a eventi esterni, sono intrise di tranquillo ottimismo, dotate di una forza intrinseca capace de trionfare anche sull'odio radicato e sul desiderio di vendetta ${ }^{23}$.

En efecto, en las novelas de caballerías el amor, sus normas cortesanas y su expresión poética, están en estrecha relación con la importancia que se otorga a las aventuras bélicas ${ }^{24}$, y en el caso concreto del Beliandro la dimensión sentimental llega a superar-

21 Finazzi-Agrò, E., A Novelística Portuguesa do Século XVI, pág. 26.

22 Vargas Díaz-Toledo, Aurelio. Os livros de cavalarias portugueses dos séculos XVI-XVIII, Lisboa, Pearlbooks, 2012, pág. 144.

23 Bognolo, Anna. La finzione rinnovata. Meraviglioso, corte e avventura nel romanzo cavalleresco del primo Cinquecento spagnolo, Pisa, Edizioni ETS, 1997, pág. 72.

24 Lucía Megías, José Manuel: “Libros de caballerías manuscritos”, Voz y Letra: Revista de literatura, VII/II, 1996, pág. 91. 
las progresivamente, un aspecto cuyo análisis pormenorizado trasciende los límites del presente trabajo.

Pedro Álvarez Cifuentes Universidad de Oviedo 